\title{
Cardioprotective Effects of Sodium-glucose Cotransporter 2 Inhibitors Regardless of Type 2 Diabetes Mellitus: A Meta-analysis
}

\author{
Lucas Silva Sousa, ${ }^{\circledR}$ Felipe de Araújo Nascimento, ${ }^{2}{ }^{\circledR}$ Juliano Rocha, ${ }^{1}{ }^{\circledR}$ Michelle Rocha-Parise ${ }^{1,2}{ }^{\oplus}$ \\ Curso de medicina, Universidade Federal de Jataí-UFJ,' Goiás, GO - Brazil \\ Programa de pós-graduação em Genética e Biologia Molecular, Universidade Federal de Goiás-UFG, ${ }^{2}$ Goiás, GO - Brazil
}

\section{Abstract}

Background: Type 2 diabetes mellitus (T2DM) is an independent risk factor for cardiovascular impairment, increasing the rates of atherosclerotic and non-atherosclerotic events. Additionally, adverse kidney events are directly linked with T2DM and cardiovascular diseases. In this context, the sodium-glucose cotransporter 2 inhibitors (SGLT2i) have demonstrated both cardioprotective and renoprotective effects in patients with or without T2DM. Therefore, the present meta-analysis aims to evaluate cardiovascular outcomes involving SGLT2i as monotherapy or other add-on antidiabetic agents (ADA) in patients with or without T2DM.

Objetive: The present meta-analysis aims to evaluate cardiovascular outcomes involving SGLT2i as monotherapy or add-on other ADA in patients with or without T2DM.

Methods: The entrance criteria to SGLT2i studies were: describing any data regarding cardiovascular effects; enrolling more than 1,000 participants; being approved by either the FDA or the EU, and having available access to the supplementary data. The trial had to exhibit at least one of the following results: major adverse cardiovascular events (MACE), cardiovascular death or hospitalization for heart failure, cardiovascular death, hospitalization for heart failure, renal or cardiovascular adverse events, or non-cardiovascular death. The significance level of 0.05 was adopted in the statistical analysis.

Results: Nine trials with a total of 76,285 participants were included in the meta-analysis. SGLT2i reduced MACE (RR 0.75, 95\% CI [0.55-1.01]), cardiovascular death or hospitalization for heart failure (RR 0.72, 95\% CI [0.55-0.93]), cardiovascular death (RR 0.66, 95\% CI [0.48-0.91]), hospitalization for heart failure (RR 0.58, 95\% CI [0.46-0.73]), renal or cardiovascular adverse events (RR 0.55, 95\% CI [0.39-0.78]), and non-cardiovascular death (RR 0.88, 95\% CI [0.60-1.00]).

Conclusions: Conjunction overall data suggests that these drugs can minimize the risk of cardiovascular events, thus decreasing mortality in patients, regardless of the presence of T2DM.

Keywords: Sodium-Gucose Transport Protein II; Heart Failure;Hospitalization; Reproducibility of Results; Outcome Assessment (Health Care); Diabetes Mellitus; Meta-Analysis.

\section{Introduction}

Around 63 million people present heart failure worldwide, ${ }^{1,2}$ and this condition costs billion dollars to health care, ${ }^{3}$ This syndrome is associated with high morbidity and mortality rates, since it has a poor prognosis due to the difficulty in recognizing high-risk and pre-clinical stage patients linked to the problem of an appropriate early treatment. ${ }^{1,4,5}$ Despite many designed trials, no adequate pharmacological treatment was found for heart failure with preserved ejection fraction $(\mathrm{EF}>50 \%)^{6-8}$, which most likely represents $65 \%$ of heart failure in $2020 .{ }^{1,6}$

Among the remarkable consequences of heart failure is the cardiorenal syndrome. ${ }^{9}$ This link is attributed to renal hypoperfusion, which is caused by high venous pressure

Mailing Address: Michelle Rocha Parise

Rodovia BR 364, km 195, Setor Parque Industrial n: 3800. Postal Code: 75801-615, Jataí, Goiás, GO - Brazil.

E-mail: microcha123@ufg.br 
and low cardiac output, leading to renal inflammation; sympathetic overstimulation; elevated sodium and consequent fluid retention; as well as atherosclerosis, anemia, and the of uremic toxins. ${ }^{1,9}$ Altogether, these pathological mechanisms enhance the risk of cardiovascular adverse events, worsening heart failure. ${ }^{1}$

Type 2 diabetes mellitus (T2DM) is a specific risk factor for atherosclerotic and non-atherosclerotic impairment responsible for myocardial diseases, such as myocardial infarction and heart failure. Furthermore, T2DM is, together with hypertension, the leading cause of chronic renal disease. ${ }^{1,10,11}$ This metabolic condition is capable of promoting injuries and alterations in the kidneys, hormone control, hepatic function, lipid metabolism, and vascular control, as well as in overstimulating the sympathetic nervous system and increasing the blood pressure. ${ }^{1,12}$

Sodium-glucose cotransporter 2 inhibitors (SGLT2i) comprise one of the newest antidiabetic agents (ADA) ${ }^{13}$ Recent studies have shown SGLT2i benefits in T2DM, such as lowering sodium and glucose retention, promoting glycosuria and weight loss, reducing glycemia, and the glycated hemoglobin ( $\mathrm{HbA} 1 \mathrm{c})$, as well as autonomic symptoms and blood pressure and the enhancement of the renal function. ${ }^{12}$ Moreover, cardiovascular benefits were seen in recent cardiovascular outcome trials (CVOTs). ${ }^{14-22}$ Such services may be attributed to SGLT2i ability to reduce left ventricular mass, ${ }^{23}$ improve systolic and diastolic functions, ${ }^{24}$ endothelial function, and cardiac output ${ }^{25}$ to reduce preload and afterload, ${ }^{26}$ to raise erythropoietin ${ }^{1}$ and to inhibit cardiac fibrosis. ${ }^{27,28}$

According to a recent paper published by the European Society of Cardiology in association with the Heart Failure Association, ${ }^{29}$ SGLT2i have proven to be the most effective ADA at reducing hospitalization for heart failure. It was demonstrated that Empagliflozin, Canagliflozin, and Dapagliflozin were responsible for decreasing hospitalization for heart failure by 35\%, 33\%, and $27 \%$, respectively. Moreover, Empagliflozin lowered the risk of cardiovascular death by $38 \%$ and presented similar performance to Canagliflozin in reducing the risk of major adverse cardiovascular events (MACE), a composite of cardiovascular death, non-fatal myocardial infarction or non-fatal stroke in $14 \%$.

Approved by the Food and Drug Administration (FDA), Canagliflozin (Invokana $\left.{ }^{\circledR}\right)^{13}$, Dapagliflozin $\left(\text { Forxiga }^{\circledR}\right)^{13}$, and Empagliflozin (Jardiance $\left.{ }^{\circledR}\right)^{13}$ were the SGLT2i tested in CVOTs. The cardioprotective effect of Ertugliflozin (Steglatro $\left.{ }^{\circledR}\right)^{30}$, the most recent SGLT2i approved by the FDA, is underway through the ongoing trial VERTIS-CV (Evaluation of Ertugliflozin Efficacy and Safety Cardiovascular Outcomes Trial) ${ }^{31}$. In turn, Sotagliflozin $\left(\right.$ Zynquista $\left.^{\circledR}\right),{ }^{32}$ recently approved by the European Medicines Agency (EU), but not by the FDA, is the first dual sodium-glucose cotransporter 1 and 2 inhibitors) and its probable cardiovascular effects are reliant on the ongoing SOLOIST-WHF (Effect of Sotagliflozin on Cardiovascular Events in Patients With Type 2 Diabetes Post Worsening). ${ }^{33}$

Most importantly, the SGLT2i effects are seen both in patients with T2DM and without T2DM. Thus, the SGLT2i benefits are independent of glucose levels. Intending to test this hypothesis, the DAPA-HF trial (Effect of Dapagliflozin on the Incidence of Worsening Heart Failure or Cardiovascular Death in Patients With Chronic Heart Failure $)^{18}$ portrayed outstanding results in its analysis through the demonstration that Dapagliflozin $10 \mathrm{mg}$ could also reduce hospitalization for heart failure regardless of the presence of T2DM. ${ }^{34-36}$

Furthermore, some ongoing trials, with more than 2,000 participants, will present their outcomes regarding patients with or without T2DM and heart failure with reduced $(\mathrm{HFrEF}-\mathrm{FE}<40 \%)^{1}$ or preserved ejection fraction (HFpEF), such as EMPEROR-Reduced (Empagliflozin Outcome Trial in Patients with Chronic Heart Failure with Reduced Ejection Fraction) ${ }^{37}$, EMPEROR-Preserved (Empagliflozin Outcome Trial in Patients with Chronic Heart Failure with Preserved Ejection Fraction) ${ }^{38}$ and DELIVER (Dapagliflozin Evaluation to Improve the Lives of Patients with Preserved Ejection Fraction Heart Failure). ${ }^{1}$ Another two ongoing trials were designed to evaluate the cardioprotective benefit of SGLT2 $i$ in chronic kidney disease patients with or without T2DM, such as DAPA-CKD (Dapagliflozin and Prevention of Adverse outcomes in Chronic Kidney Disease trial) ${ }^{39}$ and EMPA-KIDNEY (The Study for Heart and Kidney Protection with Empagliflozin) $)^{40}$.

Hence, this present meta-analysis aims to evaluate and compare the available data from the published trials regarding the cardioprotective effects of SGLT2 $i$ in patients either in the presence or absence of T2DM.

\section{Methods}

\section{Search and Selection Strategy}

First, a search was conducted on the Google Scholar, Scielo, and PubMed databases using the keywords: 
"sodium-glucose cotransporter 2 inhibitors", "heart failure", "hospitalization", and "cardiovascular outcomes". From the recovered articles of these databases, the following data were gathered: (I) author; (II) year; (III) title of the trial; (IV) the number of participants in each trial; (V) the number of participants who received the drug; (VI) the number of participants who matched placebo or other ADA; (VII) the events of MACE or hospitalization for heart failure or cardiovascular death; (VIII) the results of renal or cardiovascular adverse events [End-stage Kidney Disease, Renal Death, $\geq 40 \%$ Decrease in estimated glomerular filtration rate (eGFR) to $<60 \mathrm{~mL} /$ $\mathrm{min} / 1.73 \mathrm{~m}^{2}$, renal replacement therapy or hospitalization for heart failure, cardiovascular death, MACE]; and (IX) non-cardiovascular death.

\section{Eligibility Criteria}

The eligibility criteria of this analysis required four obligatory entrance criteria: studies with any of the SGLT2i describing any data regarding any cardiovascular effect; having enrolled more than 1,000 participants; being approved by the FDA and/or the EU; and the available access to the supplementary data. Afterward, the trial had to exhibit at least one of these following criteria: major adverse cardiovascular effects (MACE cardiovascular death, non-fatal myocardial infarction or non-fatal stroke); a composite of cardiovascular death or hospitalization for heart failure; cardiovascular death; hospitalization for heart failure; renal or cardiovascular adverse events (End-stage Kidney Disease, Renal Death, $\geq 40 \%$ decrease in estimated glomerular filtration rate (eGFR) to $<60 \mathrm{~mL} / \mathrm{min} / 1.73 \mathrm{~m}^{2}$, renal replacement therapy or hospitalization for heart failure, cardiovascular death, MACE); or non-cardiovascular death. Figure 1 summarizes the flow of the selection of articles.

\section{Statistical Analysis}

The R software ${ }^{41}$ with the "Metafor" package was used to analyze the Relative Risk (RR) among the trials to random effect through the DerSimonian method, ${ }^{42}$ classifying them in six patterns: MACE; cardiovascular death or hospitalization for heart failure; cardiovascular death; hospitalization for heart failure; renal or cardiovascular adverse events; and non-cardiovascular death. Thus, the SGLT2i group was compared to the placebo group. In addition to RR's cumulative effect, the heterogeneity index $\left(\mathrm{H}^{2}\right)$ was also analyzed for each predetermined pattern. The significance level of 0.05 was adopted in the statistical analysis.

\section{Results}

\section{Studies Characteristics}

The search retrieved ninety-three studies, nine of which fulfilled the eligibility criteria and were included
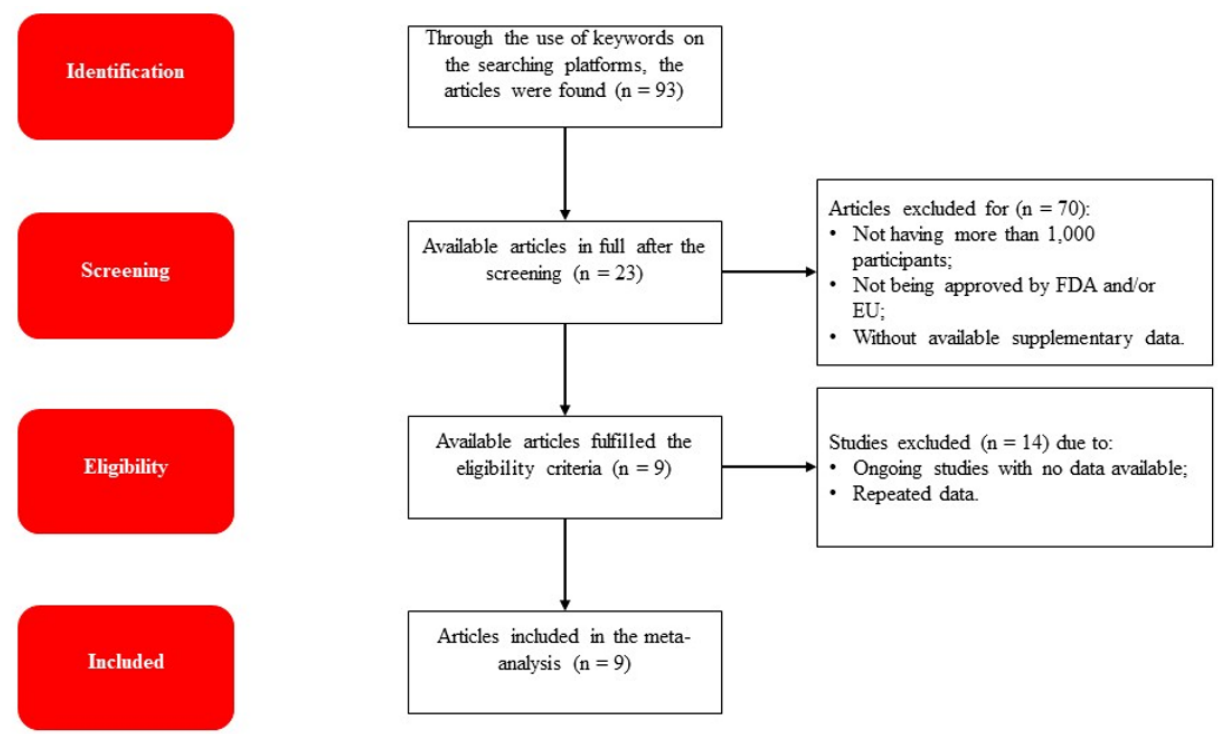

Figure 1 - Flowchart of the analyzed studies included. 
in this analysis, enrolling 76,285 participants, of whom 2,605 (approximately 3.4\%) did not have T2DM.

Of the nine studies analyzed, five investigated SGLT2i as a monotherapy: Fitcher et al. ${ }^{15}$ (Empagliflozin Cardiovascular Outcome Event Trial in Type 2 Diabetes Mellitus Patients Removing Excess Glucose - EMPAREG OUTCOME) ${ }^{15}$; Mahaffey et al. ${ }^{14}$ (Canagliflozin Cardiovascular Assessment Study - CANVAS) ${ }^{14}$; Perkovic et al., ${ }^{16}$ (Canagliflozin and Renal Events in Diabetes with Established Nephropathy Clinical Evaluation CREDENCE); ${ }^{16}$ Wiviott et al., ${ }^{17}$ (Dapagliflozin Effect on Cardiovascular Events - Thrombolysis in Myocardial Infarction 58 - DECLARE-TIMI 58), ${ }^{17}$ and McMurray et al., ${ }^{18}$ (Effect of Dapagliflozin on the Incidence of Worsening Heart Failure or Cardiovascular Death in Patients With Chronic Heart Failure - DAPA-HF). ${ }^{18}$

Three of them studied SGLT2i add-on metformin vs. other ADAs: Levalle-González et al., ${ }^{19}$ (Canagliflozin
Treatment and Trial Analysis - DDP-4 Inhibitor Comparator Trial - CANTATA-D) ${ }^{19}$; Ridderstrale et al., ${ }^{20}$ (Efficacy and Safety of Empagliflozin With Metformin in Patients With Type 2 Diabetes - EMPA-REG H2H-SU) ${ }^{20}$ and Patel et al., ${ }^{21}$ (Canagliflozin Treatment And Trial Analysis-Sulfonylurea - CANTATA-SU). ${ }^{21}$ Comparing Empagliflozin versus other Sitagliptin, EMPRISE (Empagliflozin Comparative Effectiveness and Safety) had their first analysis published by Patorno et al., ${ }^{22}$ The overall study characteristics are gathered in Table 1.

\section{Major Adverse Cardiovascular Effects}

Seven of the nine selected trials have analyzed the rate of MACE. Among these trials, the studies that used SGLT2i as monotherapy presented more robust and significant results than those using SGLT2i add-on metformin, as shown in Figure 2. Mahaffey et al., ${ }^{14}$ (CANVAS) ${ }^{14}$ and Perkovic et

Table 1 - Characteristics of the included studies at baseline

\begin{tabular}{|c|c|c|c|c|c|c|c|c|c|}
\hline $\begin{array}{l}\text { Author/ } \\
\text { Year }\end{array}$ & Trial $^{*}$ & $\begin{array}{l}\text { Follow- } \\
\text { up } \\
\text { (weeks) }\end{array}$ & $\begin{array}{c}\text { Mean } \\
\text { age } \\
\text { (years) }\end{array}$ & SGLT2inhib & ADM & Exposed & Compare & Control & Total \\
\hline $\begin{array}{l}\text { Mahaffey et } \\
\text { al., } 2018^{14}\end{array}$ & CANVAS & 338 & 63.3 & CANA & MONO & 3,756 & $\mathrm{PBO}$ & 2,039 & 5,795 \\
\hline $\begin{array}{l}\text { Fitcher et al., } \\
2016^{15}\end{array}$ & $\begin{array}{l}\text { EMPA-REG } \\
\text { OUTCOME }\end{array}$ & 162 & 63.1 & EMPA & MONO & 4,687 & $\mathrm{PBO}$ & 2,333 & 7,020 \\
\hline $\begin{array}{l}\text { Perkovic et } \\
\text { al., } 2019^{16}\end{array}$ & CREDENCE & 42 & 63.0 & CANA & MONO & 2,202 & $\mathrm{PBO}$ & 2,199 & 4,401 \\
\hline $\begin{array}{l}\text { Wiviott et } \\
\text { al., } 2018^{17}\end{array}$ & $\begin{array}{l}\text { DECLARE- } \\
\text { TIMI } 58\end{array}$ & 206 & 63.9 & DAPA & MONO & 8,582 & $\mathrm{PBO}$ & 8,578 & 17,160 \\
\hline $\begin{array}{l}\text { McMurray et } \\
\text { al., } 2019^{18}\end{array}$ & DAPA-HF & 72 & 66.0 & DAPA & MONO & 2,373 & $\mathrm{PBO}$ & 2,371 & 4,744 \\
\hline $\begin{array}{l}\text { Levalle- } \\
\text { González et } \\
\text { al, } 2013^{19}\end{array}$ & CANTATA-D & 52 & 55.4 & CANA & $\begin{array}{l}\text { Add-on } \\
\text { MET }\end{array}$ & 735 & SITA & 549 & 1,284 \\
\hline $\begin{array}{l}\text { Ridderstrale } \\
\text { et al., } 2018^{20}\end{array}$ & $\begin{array}{c}\text { EMPA-REG } \\
\text { H2H-SU }\end{array}$ & 104 & 55.9 & EMPA & $\begin{array}{l}\text { Add-on } \\
\text { MET }\end{array}$ & 765 & GLIM & 780 & 1,545 \\
\hline $\begin{array}{l}\text { Patel et al., } \\
2016^{21}\end{array}$ & CANTATA-SU & 104 & 56.2 & CANA & $\begin{array}{l}\text { Add-on } \\
\text { MET }\end{array}$ & 968 & GLIM & 482 & 1,450 \\
\hline $\begin{array}{l}\text { Patorno et } \\
\text { al., } 2019^{22}\end{array}$ & EMPRISE & 48 & 59 & EMPA & MONO & 16,443 & SITA & 16,443 & 32,886 \\
\hline Total & - & 1128 & 60.6 & - & - & 40,551 & - & 35,774 & 76,285 \\
\hline $\begin{array}{l}\text { SGLT2 inhib: } \\
\text { MONO: Mon } \\
{ }^{*} p<0.05 \text { was } t\end{array}$ & $\begin{array}{l}\text { lium-glucose Cot } \\
\text { erapy; MET: Met } \\
\text { level of significan }\end{array}$ & $\begin{array}{l}\text { porter } 2 \text { I } \\
\text { iin; } P B O \text { : } \\
\text { lopted by }\end{array}$ & $\begin{array}{l}\text { tor; EM } \\
\text { ebo; SIT } \\
\text { ticles }\end{array}$ & $\begin{array}{l}\text { Empagliflozin; } \\
\text { itagliptin; GLIN }\end{array}$ & $\begin{array}{l}\text { A: Canag } \\
\text { imepiride }\end{array}$ & in; $D A P A$ & pagliflozin; & & tion; \\
\hline
\end{tabular}


Studies

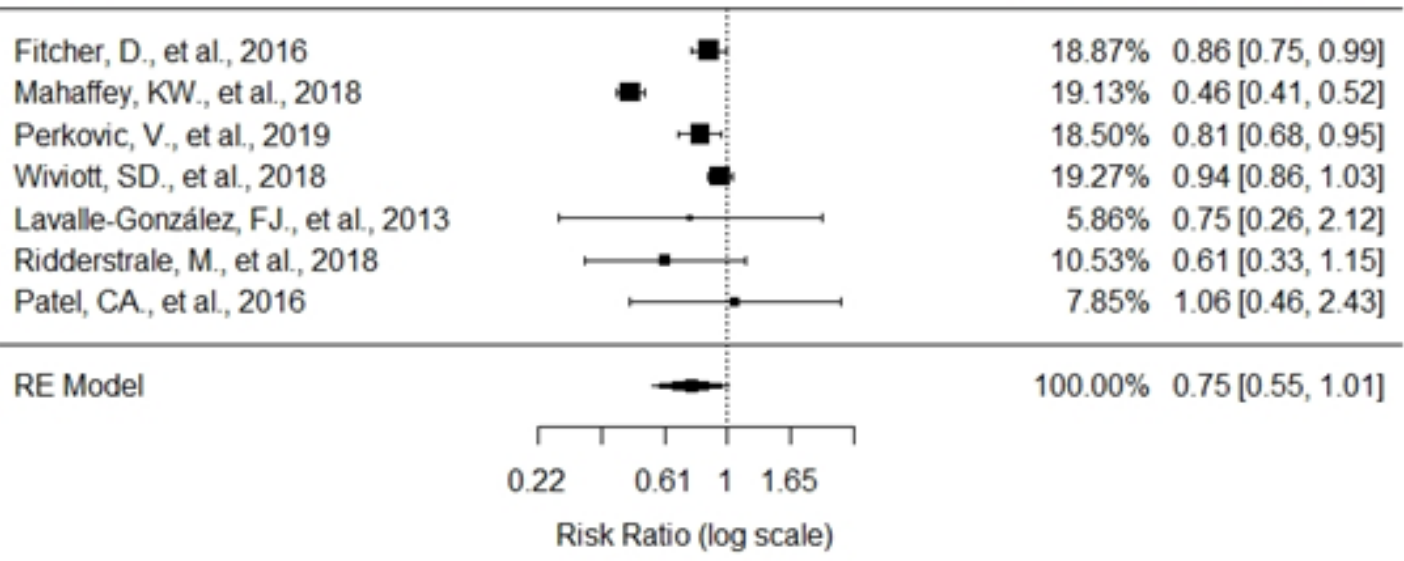

Figure 2 - Major Adverse Cardiovascular Effects (MACE).

al., ${ }^{16}$ (CREDENCE) $)^{16}$ showed the more significant and more reliable reductions of MACE with Canagliflozin 100 or $300 \mathrm{mg}$ than placebo. Similarly, Empagliflozin 10 or $25 \mathrm{mg}$ and Dapagliflozin $10 \mathrm{mg}$ also reduced this event as shown by Fitcher et al., ${ }^{15}$ (EMPA-REG OUTCOME) ${ }^{15}$ and Wiviott et al., ${ }^{17}$ (2018) (DECLARE-TIMI 58). ${ }^{17}$

On the other hand, SGLT2i add-on metformin therapy vs. other ADA decreased MACE episodes, which can be noticed through Levalle-González et al., ${ }^{19}$ (CANTATA-D) ${ }^{19}$ with Canagliflozin 100 or 300 mg add-on metformin vs. Sitagliptin $100 \mathrm{mg}$ and Ridderstrale et al. ${ }^{20}$ (EMPA-REG H2H-SU) ${ }^{20}$ with Empagliflozin 25 mg addon metformin vs. Glimepiride 1 to $4 \mathrm{mg}$. However, these two studies had a large range of confidence intervals. In turn, Patel et al., ${ }^{21}$ (CANTATA-SU) ${ }^{21}$ displayed that Canagliflozin 100 or $300 \mathrm{mg}$ add-on metformin did not show to be effective at reducing MACE when compared with Glimepiride 6 to $8 \mathrm{mg}$.

In general, SGLT2 $i$ performed further effectiveness at reducing MACE than control, placebo, or other ADA, RR $0.75,95 \%$ CI [0.55-1.01]. The heterogeneity $\left(\mathrm{I}^{2}\right)$ found was $94.02 \%$.

\section{Cardiovascular Death or Hospitalization for Heart Failure}

Five of the analyzed trials presented the data regarding cardiovascular death or hospitalization for heart failure; all employed SGLT2i as monotherapy. At first, Canagliflozin 100 or 300 mg was more effective in lowering this parameter than the placebo through the data presented by Mahaffey et al., ${ }^{14}$ (CANVAS) ${ }^{14}$ and Perkovic et al., ${ }^{16}$ (CREDENCE) ${ }^{16}$ Likewise, Wiviott et al., ${ }^{17}$ (2018) (DECLARE-TIMI 58) ${ }^{17}$ and McMurray et al., ${ }^{18}$ (2019) (DAPA-HF) ${ }^{18}$ showed a reduction of the episodes of cardiovascular death or hospitalization for heart failure with Dapagliflozin $10 \mathrm{mg}$ as well. By contrast, Fitcher et al., ${ }^{15}$ (EMPA-REG OUTCOME) ${ }^{15}$ did not observe a significant decrease in these events by the administration of Empagliflozin 10 or $25 \mathrm{mg}$. Considering all the five studies together, there was a reduction of cardiovascular death or hospitalization for heart failure (RR 0.72, 95\% CI [0.55-0.93]) generally (Figure 3 ), and the heterogeneity $\left(\mathrm{I}^{2}\right)$ was $93.72 \%$.

\section{Cardiovascular Death}

Eight of all the selected studies evaluated the cardiovascular death parameter. The greater power among the studies involving the evaluation of cardiovascular death was assured by the SGLT2i-monotherapy studies and the most significant reductions. Regarding SGLT2imonotherapy studies, Canagliflozin 100 or $300 \mathrm{mg}$ and Empagliflozin 10 or $25 \mathrm{mg}$ proved to be the most effective at reducing cardiovascular death events according to Mahaffey et al., ${ }^{14}$ (CANVAS) ${ }^{14}$ and Fitcher et al., ${ }^{15}$ (EMPAREG OUTCOME). ${ }^{15}$ In the same manner, Mahaffey $\mathrm{K}$ 
Studies

Weight and RR $[95 \% \mathrm{Cl}]$

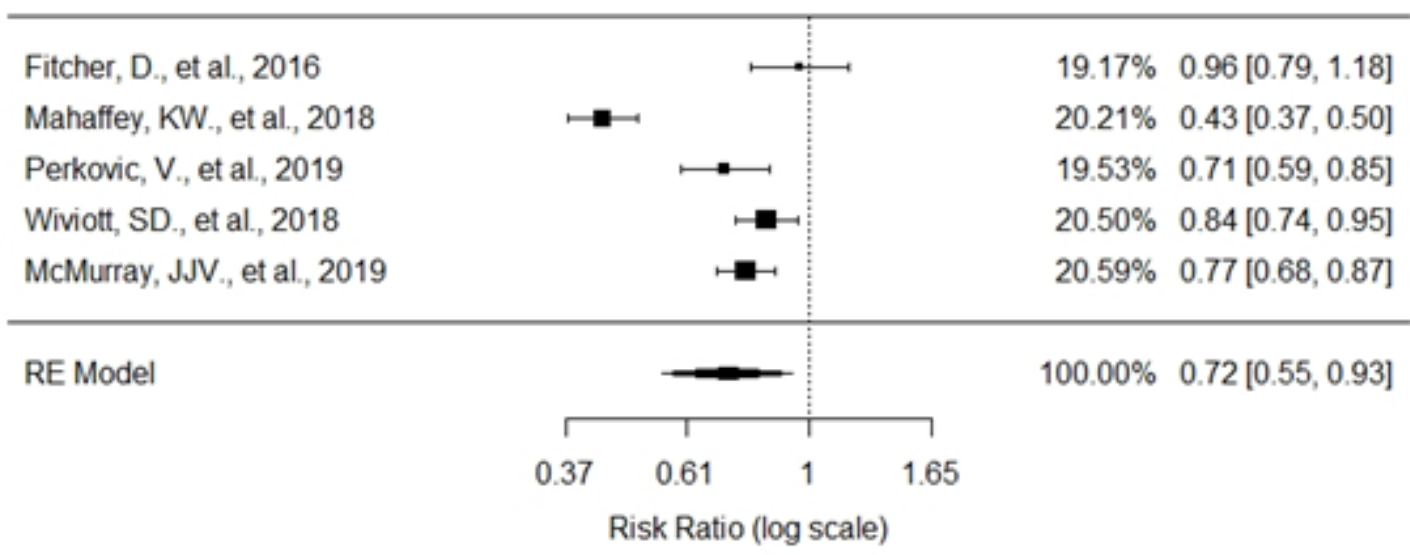

Figure 3 - Cardiovascular Death or Hospitalization for Heart Failure.

Studies

Fitcher, D., et al., 2016

Mahaffey, KW., et al., 2018

Perkovic, V., et al., 2019

Wiviott, SD., et al., 2018

McMurray, JJV., et al., 2019

Lavalle-González, FJ., et al., 2013

Ridderstrale, M., et al., 2018

Patel, CA. et al., 2016
Weight and RR $[95 \% \mathrm{CD}]$

$18.36 \% \quad 0.43[0.35,0.53]$

$18.68 \% 0.45[0.38,0.54]$

$17.73 \% 0.78[0.62,1.00]$

$18.67 \% 0.98[0.83,1.17]$

$18.76 \% \quad 0.83[0.70,0.98]$

$1.62 \% \quad 0.37[0.03,4.11]$

$3.00 \% \quad 0.51[0.09,2.78]$

$3.18 \% 1.24[0.24,6.39]$

$100.00 \% \quad 0.66[0.48,0.91]$

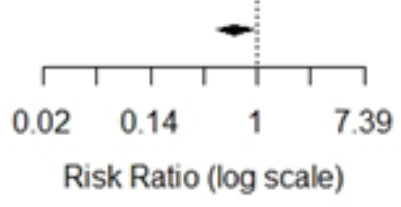

Figure 4 - Cardiovascular Death.

et al., ${ }^{16}$ (CANVAS), ${ }^{16}$ Perkovic et al., ${ }^{16}$ (CREDENCE) $)^{16}$ presented a consistent reduction in cardiovascular death promoted by Canagliflozin 100 or $300 \mathrm{mg}$. However, the use of Dapagliptin $10 \mathrm{mg}$ did not result in a consistent reduction of this event, as demonstrated by Wiviott et al., ${ }^{17}$ (DECLARE-TIMI 58) ${ }^{17}$ and McMurray et al., ${ }^{18}$ (DAPA-HF). ${ }^{18}$
Despite the apparent benefit of SGLT2i add-on metformin, the studies using a combined therapy had a wide confidence interval. This is shown with the use of Canagliflozin 100 or $300 \mathrm{mg}$ add-on metformin vs Sitagliptin $100 \mathrm{mg}$ demonstrated by Levalle-González et al., ${ }^{19}$ (CANTATA-D), ${ }^{19}$ Empagliflozin $25 \mathrm{mg}$ add-on metformin vs Glimepiride 1 to $4 \mathrm{mg}$ by Ridderstrale et 
al., ${ }^{20}$ (EMPA-REG H2H-SU) ${ }^{20}$ and Canagliflozin 100 or $300 \mathrm{mg}$ add-on metformin vs Glimepiride 6 to $8 \mathrm{mg}$ by Patel et al., ${ }^{21}$ (CANTATA-SU). ${ }^{21}$

Although the heterogeneity $\left(\mathrm{I}^{2}\right)$ among the data was $89.43 \%$, the general evaluation showed that the use of SGLT2i causes a significant reduction in cardiovascular deaths (RR 0.66, 95\% CI [0.48-0.91]) (Figure 4).

\section{Hospitalization for Heart Failure}

Seven of the evaluated studies displayed the hospitalization for heart failure parameter. In general, SGLT2i administration led to a lower rate of hospitalization for heart failure (RR 0.60, 95\% CI [0.47-0.77]) (Figure 5). Ridderstrale et al., ${ }^{20}$ (EMPA-REG H2H-SU) ${ }^{20}$ was the only SGLT2i add-on metformin study to evaluate this parameter. In its data, Emplagliflozin $25 \mathrm{mg}$ add-on metformin compared to Glimepiride 1 to $4 \mathrm{mg}$ showed a broad confidence interval in reducing this event as.

By contrast, SGLT2i, as a monotherapy, presented more consistent and significant results. At first, Canagliflozin 100 or $300 \mathrm{mg}$ showed the highest reduction in hospitalization for heart failure among the SGLT2i, according to the data from Mahaffey et al., ${ }^{14}$ (CANVAS). ${ }^{14}$ Similarly, Patorno et al., ${ }^{22}$ (EMPRISE) ${ }^{22}$ reported a substantial reduction of hospitalization for heart failure through the use of Empagliflozin $25 \mathrm{mg}$, revealing a superiority of SGLT2i over Sitagliptin. Perkovic et al., ${ }^{16}$ (CREDENCE) $)^{16}$ also demonstrated that Canagliflozin 100 or $300 \mathrm{mg}$ resulted in a lower hospitalization for heart failure. Similarly, Fitcher et al.,15 (EMPA-REG OUTCOME $)^{15}$ reported a reduction in hospitalization for heart failure with Empagliflozin 10 or $25 \mathrm{mg}$.

In turn, Dapagliflozin $10 \mathrm{mg}$ administration decreased hospitalization for heart failure, producing similar results to those obtained by Wiviott et al., ${ }^{17}$ (DECLARE-TIMI $58)^{17}$ and McMurray J et al., ${ }^{18}$ (DAPA-HF) ${ }^{18}$ highlighting the fact of McMurray et al., ${ }^{18}$ (DAPA-HF) ${ }^{18}$ enrolled only $45 \%$ of T2DM participants (Table1), indicating the potential benefit of this medication to prevent and treat heart failure events, regardless of T2DM presence. The heterogeneity identified was $82.99 \%$.

\section{Renal or Cardiovascular Adverse Events}

Four of the selected studies, all of which were SGLT2i monotherapy studies, evaluated the renal or cardiovascular adverse events. In general, SGLT2i reduced these outcomes in $45 \%$ (RR 0.55, 95\% CI [0.39-0.78]) (Figure 6). The most effective medications at reducing this outcome were Empagliflozin 10 or $25 \mathrm{mg}$ and Canagliflozin 100 or $300 \mathrm{mg}$ as highlighted by Fitcher et al., ${ }^{15}$ (EMPA-REG
Studies

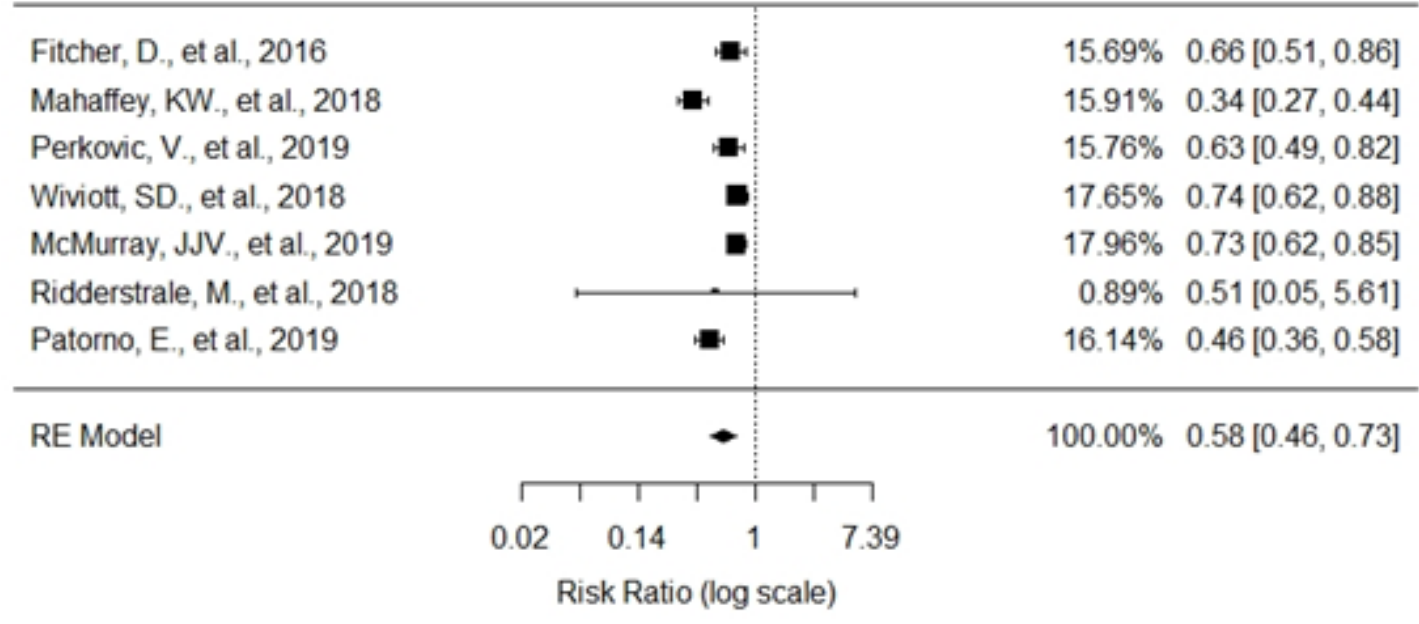


OUTCOME) ${ }^{15}$ and Mahaffey et al., ${ }^{14}$ (CANVAS). ${ }^{14}$ Perkovic et al., ${ }^{16}$ (CREDENCE), ${ }^{16}$ despite showing a smaller protective effect as compared to the studies cited above, also showed a consistent reduction with Canagliflozin 100 or $300 \mathrm{mg}$, similarly to Empagliflozin 10 or $25 \mathrm{mg}$ by Wiviott et al., ${ }^{17}$ (DECLARE-TIMI 58). ${ }^{17}$ The heterogeneity found was $96.77 \%$.

\section{Non-cardiovascular Death}

Four of the trials registered non-cardiovascular deaths, all four of which were SGLT2i-monotherapy studies. Although the results were not the most consistent, SGLT2i seemed to reduce non-cardiovascular death (RR 0.88, 95\% CI [0.60-1.00]), especially Dapagliglozin $10 \mathrm{mg}$, as reported by Wiviott et al., ${ }^{17}$ (DECLARE-TIMI 58) ${ }^{17}$ (Figure 7). However, McMurray et al., ${ }^{18}$ (DAPA-HF), ${ }^{18}$ using the same dose of this medication, did not present such promising results. Fitcher et al., ${ }^{15}$ (EMPA-REG OUTCOME) ${ }^{15}$ and Perkovic et al., ${ }^{16}$ (CREDENCE) ${ }^{16}$ presented similar effects regarding non-cardiovascular death. No heterogeneity was found due to the overlap of the confidence interval between studies $\left(\mathrm{I}^{2}=0 \%\right)$.

\section{Discussion}

SGLT2i presents promising effects concerning the protection of the cardiovascular system. ${ }^{1,13}$ This class of drugs lowered MACE, the composite of cardiovascular death or hospitalization for heart failure, cardiovascular death, hospitalization for heart failure, and non-cardiovascular death. All these reductions were seen in patients with cardiovascular and/or kidney injuries and in patients with a high risk for these conditions, which shows that these drugs can be used in primary prevention. Still, it is essential to highlight that the SGLT2i monotherapy studies exerted the most noteworthy outcomes.

Regardless of T2DM presence, McMurray et al., ${ }^{18}$ $\left(\right.$ DAPA-HF) ${ }^{18}$ showed that the use of Dapagliflozin 10 $\mathrm{mg}$ reduced the composite of cardiovascular death or hospitalization for heart failure, cardiovascular death, hospitalization for heart failure and non-cardiovascular death. In accordance with Milder et al., ${ }^{43}$ and Heerspink et al., ${ }^{44}$ such benefits can be elucidated due to the dissociation between hypoglycemic and cardioprotective effects exerted by SGLT2i. The probable mechanisms are weight loss, ${ }^{43,45}$ reduced blood pressure, ${ }^{43,46-49}$ reduced preload and afterload, ${ }^{23,26,43,50,51}$ natriuresis, and osmotic diuresis, ${ }^{23,43}$ inhibition of sodium-hydrogen exchanger in the myocardium, ${ }^{43,52-54}$ induced ketone bodies for cardiac metabolism, ${ }^{43,55}$ reduced cardiac fibrosis, ${ }^{27,28,43}$ and reduced adipose inflammatory cytokines. ${ }^{43,56}$ All these mechanisms are uncoupled from glycemic levels and kidney function. However, Vallon et al., ${ }^{57}$ and Chao $\mathrm{E}^{58}$ showed that the natriuresis and osmotic diuresis caused by glycosuria are the most robust mechanisms in reducing cardiovascular adverse events.

Although SGLT2 $\mathrm{i}$ lowered all the analyzed parameters, the monotherapy study outcomes ${ }^{14-18,22}$ seemed to be

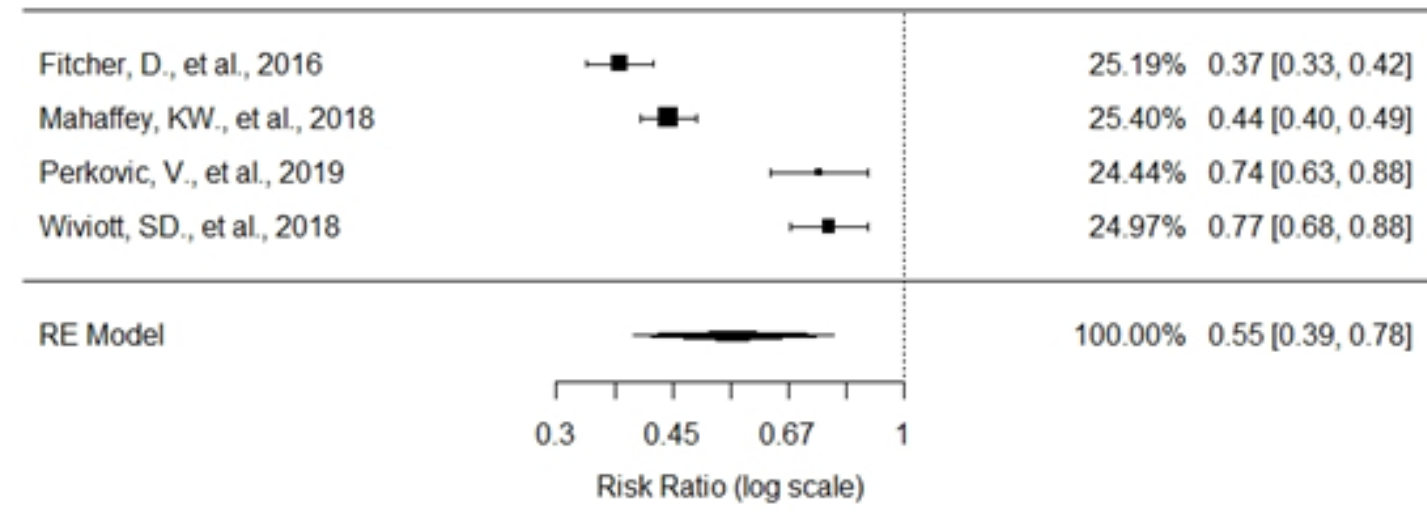


Studies

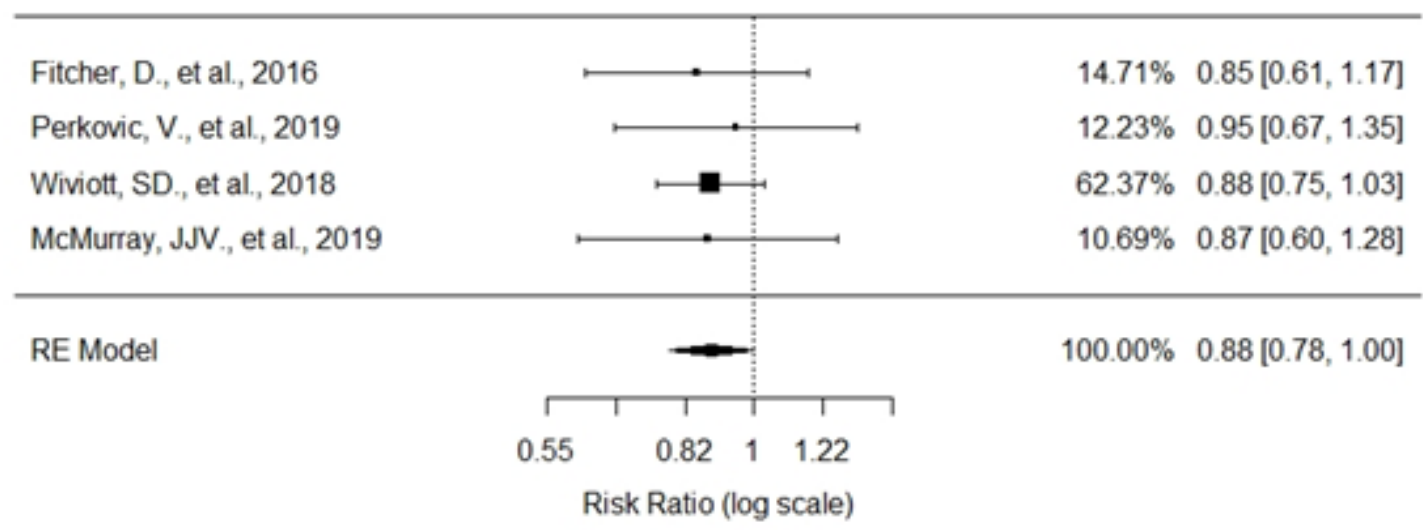

Figure 7 - All-cause of Death.

superior to SGLT2i add-on metformin study outcomes. ${ }^{19-21}$ However, to date, there is no evidence proving that monotherapy is more promising than add-on therapy. There is a lack of robust CVOTs evaluating SGLT2i addon therapy's effect, and no medical association ${ }^{1,2,8,9,29}$ has described either of them. The majority of SGLT2i add-on therapy studies ${ }^{19-21}$ were designed to assess this therapy's impact regarding glycemia, glycated hemoglobin, and blood pressure reductions, which indirectly affects the cardiovascular system. Therefore, the direct cardiovascular effects of SGLT2i add-on therapy have not yet been consistently proven.

Regarding the benefits of SGLT2 $i$ in treating cardiovascular autonomic neuropathy in T2DM patients, Spallone $\mathrm{V}^{12}$ showed that these drugs could improve the signs and symptoms of sympathetic overstimulation. The improvement of cardiovascular system effects would occur through natriuretic development, glycosuria, weight-loss, anti-inflammatory action, tyrosine hydroxylase, and kidney and heart noradrenaline inhibition, reducing hypertension, tachycardia, exercise intolerance, and orthostatic symptoms at rest.

Saleem, ${ }^{13}$ and Fioretto et al., ${ }^{59}$ found that the SGLT2i could perform protection in the kidney and heart through a minor risk of atherosclerotic events, volume contraction and blood pressure, and preload and afterload reduction. The authors also presented that dapagliflozin could be well-tolerated when co-administered with common medications to treat other comorbidities and could benefit from low and high cardiovascular risk profiles. By contrast, no reduction in stroke events was noticed by the use of SGLT2i.

Moreover, Elmore et al., ${ }^{60}$ presented that the SGLT2i would be involved in several biochemical mechanisms, which reduced cardiovascular events, such as MACE, atherosclerotic diseases, and hospitalization for heart failure, including the possible reduction of left ventricular ejection fraction. On the other hand, Canagliflozin did not display an improvement in cardiovascular diseases, and its side and adverse effects did not surpass its efficacy (Mosleh et al., ${ }^{61}$ ) Comparing the results of Dipeptidyl Peptidase 4 (DPP-4) Inhibitor studies to SGLT2i studies, the Savarese et al., ${ }^{62}$ meta-analysis, evaluating 157 trials, showed that the use of DPP-4 Inhibitors did not result in a reliable reduction into all-cause death, cardiovascular death, myocardial infarction and hospitalization for heart failure. Still, they could decrease stroke events, mostly as compared to placebo. Conversely, SGLT2i reduced allcause death, cardiovascular death, myocardial infarction, and hospitalization for heart failure. However, a higher risk of non-fatal stroke was associated with SGLT2i use.

Similarly, Wu et al., ${ }^{63}$ portrayed, through 57 studies and six regulatory submissions included within their meta-analysis, the benefits of SGLT2i to MACE, cardiovascular death, hospitalization for heart failure, and all-cause of death. Furthermore, they reported the potential higher risk of non-fatal stroke due to SGLT2 $i$ administration and no statistical effect related 
to myocardial infarction. Meanwhile, a meta-analysis employing 71 studies designed by Monami et al., ${ }^{64}$ showed that SGLT2i lowered the all-cause death, cardiovascular death, and myocardial infarction, whereas no significant reduction was seen in stroke.

Recently, Zelniker et al., ${ }^{65}$ in their meta-analysis of three SGLT2 $i$ trials vs. placebo, found that SGLT2 $i$ had a powerful effect in reducing MACE, myocardial infarction, cardiovascular death, hospitalization for heart failure, all-cause of death, and the composite of worsening of renal function, end-stage renal disease or renal death, and hospitalization for heart failure in those participants with a worse estimated glomerular filtration rate (eGFR). However, these remarkable results were better seen in the subgroup of patients with the atherosclerotic disease than the subset of patients with multiple risk factors, and no benefit was found in reducing rates of stroke.

Cai-Yan Zou et al., ${ }^{66}$ in their meta-analysis involving 42 studies about SGLT2i and their benefits to the cardiovascular system showed that 37 studies showed the SGLT2i, mostly add-on metformin, reduced MACE, whereas 25 SGLT2i studies, primarily as monotherapy and add-on metformin vs. other ADA, reduced myocardial infarction events. Twentysix studies pointed out that SGLT2i was not effective at reducing stroke episodes. SGLT2i lowered cardiovascular death, mostly as a monotherapy and add-on metformin vs. other ADA, and all-cause mortality, primarily as monotherapy, through the analysis of thirteen and twenty-five studies, respectively. Similarly, our study also evaluated the impact of SGLT2i on MACE, but not apart from cardiovascular death, non-fatal stroke, and non-fatal myocardial infarction. On the other hand, our study evaluated this class's effect regarding hospitalization due to heart failure, which is widely investigated today by a wide range of ongoing trials, including the possible benefit regardless of T2DM presence.

Birkeland et al., ${ }^{67}$ brought some data from the CVD-REAL Nordic, a multinational analysis of data collected from Denmark, Norway, and Sweden Health Care System. In this article, 22,830 participants started to use SGLT2i and 68,490 participants in other ADA. Cardiovascular death, MACE, hospitalization for heart failure, and all-cause death rates were decreased after the administration of SGLT2i. However, the same was not observed with non-fatal myocardial infarction and non-fatal stroke.
Regarding the high heterogeneity index observed in the present study for all the evaluated parameters, except for the analysis of non-cardiovascular death, several variables justify these values, such as the different medicines employed in the studies (Canagliflozin, Empagliflozin, Dapagliflozin) as monotherapy or other add-on ADAs, in various specific dosages (300, 100, 25, and $10 \mathrm{mg}$ ), administered to different population groups (high-risk factors, presence of atherosclerotic disease, with or without heart failure and with or without diabetes), and low k-study values, such as these are recent clinical trials. On the other hand, it is important to emphasize that the 9 studies analysed enrolled a total of 76,285 participants. Besides, in order to increase the reliability of the study, we selected the studies which comprehended over 1,000 participants.

\section{Conclusion}

SGLT2 $\mathrm{i}$ is a promising class of drugs, since it is related to favorable cardiovascular outcomes. Thus, this class is a potent treatment candidate for cardiovascular illnesses and hopefully will soon be available for this goal if future trials continue to present such benefits.

\section{Author contributions}

Conception and design of the research: Sousa LS, Nascimento FA, Rocha J, Rocha-Parise M. Acquisition of data: Sousa LS, Nascimento FA. Analysis and interpretation of the data: Sousa LS, Nascimento FA. Statistical analysis: Nascimento FA. Writing of the manuscript: Sousa LS, Rocha J, Rocha-Parise M. Critical revision of the manuscript for intellectual content: Rocha J, Rocha-Parise M.

\section{Potential Conflict of Interest}

No potential conflict of interest relevant to this article was reported.

\section{Sources of Funding}

There were no external funding sources for this study.

\section{Study Association}

This study is not associated with any thesis or dissertation work.

\section{Ethics approval and consent to participate}

This article does not contain any studies with human participants or animals performed by any of the authors. 


\section{References}

1. Lam CSP, Chandramouli C, Ahooja V, Verma S. SGLT-2 Inhibitors in heart failure: current management, unmet needs, and therapeutic prospects. J Am Heart Assoc. 2019;8(20):1-12.

2. GBD 2016 Disease and Injury Incidence and Prevalence Collaborators. Global, regional, and national incidence, prevalence, and years lived with disability for 328 diseases and injuries for 195 countries, 1990-2016: a systematic analysis for the Global Burden of Disease Study 2016. Lancet. 2017;390(10100):1211-59.

3. Ponikoski P, Voors AA, Anker SD, Bueno H, Cleland JGF, Coats AJS, et al. 2016 ESC Guidelines for the diagnosis and treatment of acute and chronic heart failure : The Task Force for the diagnosis and treatment of acute and chronic heart failure of the European Society of Cardiology (ESC)Developed with the special contribution of the Heart Failure Association (HFA) of the ESC. Eur Heart J. 2016;37(27):2129-2200.

4. Huelsmann M, Neuhold S, Resl M, Strunk G, Brath H, Francesconi C, et al PONTIAC (NT-proBNP selected preventin of cardiac events in a population of diabetic patients without a history of cardiac disease): a prospective randomized controlled trial. J Am Coll Cardiol. 2013;62(15):1365-72.

5. Ledwidge M, Gallagher J, Conlon C, Tallon E, O'Connell E, Dawkins I, et al. Natriuretic peptide-based screening and collaborative care for heart failure: the STOP-HF randomized trial. JAMA. 2013;310(1):66-74.

6. Oktay AA, Rich JD, Shah SJ. The emerging epidemic of heart failure with preserved ejection fraction. Curr Heart Fail Rep. 2013;10(4):401-10.

7. Ouwerkerk W, Voors AA, Anker SD, Cleland JG, Dickstein K, Filippatos $\mathrm{G}$, et al. Determinants and clinical outcome of uptitration of ACEinhibitors and beta-blockers in patients with heart failure: a prospective European study. Eur Heart J. 2017;38(24): 1883-90.

8. Shah KS, Xu H, Matsouaka RA, Bhatt DL, Heidenreich PA, Hernandez $\mathrm{AF}$, et al. Heart failure with preserved, borderline, and reduced ejection fraction: 5-Year Outcomes. J Am Coll Cardiol. 2017;70(20):2476-86.

9. Ronco C, Haapio M, House AA, Anavekar N, Bellomo R. Cardiorenal syndrome. J Am Coll Cardiol. 2008;52(19):1527-39.

10. Nichols GA, Hillier TA, Erbey JR, Brown JB. Congestive heart failure in type 2 diabetes. Diabetes Care. 2001;24(9):1614-9.

11. Cavender M, Steg PG, Smith Jr SC, Eagle K, Ohman EM, Goto S, et al. Impact of diabetes mellitus on hospitalization for heart failure, cardiovascular events, and death/outcomes at 4 years from the Reduction of Atherothrombosis Continued Health (REACH) registry. Circulation. 2015;132(10):923-31.

12. Spallone V. Update on the impact, diagnosis, and management of cardiovascular autonomic neuropathy in diabetes: what is defined, what is new, and what is unmet. Diabetes Metab J. 2019;43(1):3-30.

13. Saleem F. Dapagliflozin: cardiovascular safety and benefits in type 2 diabetes mellitus. Cureus. 2017;9(10):e1751.

14. Mahaffey K, Neal B, Perkovic V, Zeeuw D, Fulcher G, Erondu N, et al. Canagliflozin for primary and secondary prevention of cardiovascular events: results from the CANVAS program (Canagliflozin Cardiovascular Assessment Study). Circulation. 2018;137(4):323-34.

15. Fitchett D, Zinman B, Wanner C, Lachin JM, Hantel S, Salsali A, et al. Heart failure outcomes with empagliflozin in patients with type 2 diabetes at high cardiovascular risk: results of the EMPA-REG OUTCOME trial. Eur Heart J. 2016;37(19):1526-34.

16. Perkovic V, Jardine MJ, Neal B, Bompoint S, Heerspink HJL, Charytan $\mathrm{DM}$, et al. Canagliflozin and renal outcomes in type 2 diabetes and nephropathy. N Engl J Med. 2019;380(24):2295-306.

17. Wiviott S, Raz I, Bonaca MP, Mosenzon O, Kato ET, Cahn A, et al Dapagliflozin and cardiovascular outcomes in type 2 diabetes. N Engl J Med. 2019;380(4):347-57.

18. McMurray J, Solomon SD, Inzucchi SE, Køber L, Kosiborod MN, Martinez FA, et al. Dapagliflozin in patients with heart failure and reduced ejection fraction. N Engl J Med. 2019;381(21):1995-2008.
19. Lavalle-González FJ, Januszewicz A, Davidson J, Tong C, Qiu R, Canovatchel W, et al. Efficacy and safety of canagliflozin compared with placebo and sitagliptin in patients with type 2 diabetes on background metformin monotherapy: a randomized trial. Diabetologia. 2013;56(12):2582-92.

20. Ridderstrale M, Rosenstock J, Andersen KR, Woerle HJ, Salsali A, EMPA-REG H2H-SU Trial Investigators. Empagliflozin compared with glimepiride in metformin-treated patients with type 2 diabetes: 208-week data from a masked randomized controlled trial. Diabetes Obes Metab. 2018;20(12):2768-77.

21. Patel C, Bailey RA, Vijapurkar U, Meininger G, Blonde L. A post-hoc analysis of the comparative efficacy of canagliflozin and glimepiride in the attainment of type 2 diabetes-related quality measures. BMC Health Serv Res. 2016;16(a):356.

22. Patorno E, Pawar A, Franklin JM, Najafzadeh M, Déruaz-Luyet A, Brodovicz KG, et al. Empagliflozin and the risk of heart failure hospitalization in routine clinical care: a first analysis from the EMPRISE Study. Circulation. 2019;139(25):2822-30.

23. Verma S, McMurray JJV, Cherney DZI. The metabolodiuretic promise of sodium-dependent glucose cotransporter 2 inhibition: the search for the sweet spot in heart failure. JAMA Cardiol. 2017;2(9):939-40.

24. Soga F, Tanaka H, Tatsumi K, Mochizuki Y, Sano H, Toki H, et al. Impact of dapagliflozin on left ventricular diastolic function of patients with type 2 diabetic mellitus with chronic heart failure. Cardiovasc Diabetol. 2018;17(1):132.

25. Sena C, Pereira AM, Seiça R. Endothelial dysfunction - a major mediator of diabetic vascular disease. Biochem Biophys Acta. 2013;1832(12):2216-31.

26. Hallow KM, Helmlinger G, Greasley PJ, McMurray JJV, Boulton DW. Why do SGLT2 inhibitors reduce heart failure hospitalization? A differential volume regulation hypothesis. Diabetes Obes Metab. 2018;20(3):479-87.

27. Travers J, Kamal FA, Robbins J, Yutzey KE, Blaxall BC. Cardiac fibrosis/ a fibroblastic awakens. Circ Res. 2016;118(6):1021-40.

28. Lee TM, Chang NC, Lin SZ. Dapagliflozin, a selective SGLT2 inhibitor, attenuated cardiac fibrosis by regulating the macrophage polarization via STAT3 signaling in infarcted rat hearts. Free Radic Biol Med. 2017 Mar;104:298-310.

29. Seferovic PM, Coats AJS, Ponikowski P, Filippatos G, Huelsmann M, Jhund PS, et al. European Society of Cardiology/Heart Failure Association position paper on the role and safety of new glucoselowering drugs in patients with heart failure. Eur J Heart Fail. 2020;22(2):196-213.

30. Al-Jobori H, Daniele G, Cersosimo E, Triplitt C, Mehta R, Norton $\mathrm{L}$, et al. Empagliflozin and kinetics of renal glucose transport in healthy individuals and individuals with type 2 diabetes. diabetes. 2017;66(7):1999-2006.

31. Heise T, Seman L, Macha S, Jones P, Marquart A, Pinnetti S, et al. Safety, tolerability, pharmacokinetics and pharmacodynamics following 4 weeks' treatment with empagliflozin once daily in patients with type 2 diabetes. Diabetes Ther. 2013;4(2):331-45.

32. Seman L, Macha S, Nehmiz G, Simons G, Ren B, Pinnetti S, et al Empagliflozin (BI 10773), a potent and selective SGLT2 inhibitor, induces dose-dependent glucosuria in healthy subjects. Clin Pharmacol Drug Dev. 2013;2(2):152-61.

33. Markham A. Ertugliflozin: first global approval. Drugs. 2018;78(4):513-9.

34. Cannon CP, McGuirre DK, Pratley R, Dagogo_Jack S, Mancuso J, Huyck S, et al. Design and baseline characteristics of the eValuation of ERTugliflozin effIcacy and safety CardioVascular outcomes trial (VERTIS-CV). Am Heart J. 2018 Dec;206:11-23.

35. Markham A, Keam SJ. Sotagliflozin: first global approval. Drugs. 2019;79(9):1023-29. 
36. Cefalo CMA, Cinti F, Moffa S, Impronta F, Sorice GP, Mezza T, et al. Sotagliflozin, the first dual SGLT inhibitor: current outlook and perspectives. Cardiovasc Diabetol. 2019;18(1):20

37. Anker SD, Buttler J, Filippatos GS, Jamal W, Salsali A, Schnee J, et al. Evaluation of the effects of sodium-glucose cotransporter 2 inhibition with empagliflozin on morbidity and mortality in patients with chronic heart failure and a preserved ejection fraction: rationale for and design of the EMPEROR-Preserved Trial. Eur J Heart Fail. 2019;21(10):1279-87.

38. Packer M, Butler J, Filippatos GS, Jamal W, Salsali A, Schnee J, et al. Evaluation of the effect of sodium-glucose cotransporter 2 inhibition with empagliflozin on morbidity and mortality of patients with chronic heart failure and a reduced ejection fraction: rationale for and design of the EMPEROR-Reduced Trial. Eur J Heart Fail. 2019;21(10):1270-8.

39. Heerspink HJL, Stefansson BV, Chertow GM, Correa-Rotter R, Greene T, Hou FF. et al. Rationale and protocol of the dapagliflozin and prevention of adverse outcomes in chronic kidney disease (DAPA-CKD) randomized controlled trial. Nephrol Dial Transplant. 2020;35(2):274-82.

40. Herrington WG, Preiss D, Haynes R, Eynatten M, Staplin N, Hauske SJ, et al. The potential for improving cardio-renal outcomes by sodium-glucose co-transporter-2 inhibition in people with chronic kidney disease: a rationale for the EMPA-KIDNEY study. Clin Kidney J. 2018;11(6):749-61.

41. R Core Team. R: A language and environment for statistical computing [Internet]. Viena: R Foundation for Statistical Computing; 2020 [citado 24 abril 2020]. Disponível em: https://www.R-project.org/.

42. DerSimonian R, Kacker R. Random-effects model for meta-analysis of clinical trials: an update. Contemp Clin Trials. 2007;28(2):105-14.

43. Milder T, Stocker SL, Samocha-Bonet D, Day RO, Greenfield JR. Sodiumglucose cotransporter 2 inhibitors for type 2 diabetes-cardiovascular and renal benefits in patients with chronic kidney disease. Eur J Clin Pharmacol. 2019;75(11):1481-90.

44. Heerspink HJL, Kosiborod M, Inzucchi SE, Cherney DZI. Renoprotective effects of sodium-glucose cotransporter-2 inhibitors. Kidney Int. 2018;94(1):26-39.

45. Zaccardi F, Webb DR, Htike ZZ, Youssef D, Khunti K, Davies MJ. Efficacy and safety of sodium-glucose co-transporter-2 inhibitors in type 2 diabetes mellitus: systematic review and network meta-analysis Diabetes Obes Metab. 2016;18(8):783-94.

46. Cherney DZI, Cooper ME, Tikkanen I, Pfarr E, Johansen OE, Woerle HJ, et al. Pooled analysis of phase III trials indicate contrasting influences of renal function on blood pressure, body weight, and $\mathrm{HbA} 1 \mathrm{c}$ reductions with empagliflozin. Kidney Int. 2018;93(1):231-44.

47. Petrykiv S, Sjöström CD, Greasley PJ, Xu J, Persson F, Heerspink HJL. Differential effects of dapagliflozin on cardiovascular risk factors at varying degrees of renal function. Clin J Am Soc Nephrol. 2017;12(5):7519.

48. Dekkers CCJ, Wheeler DC, Sjöström CD, Stefansson BV, Cain V, Heerspink HJL. Effects of the sodium-glucose cotransporter 2 inhibitor dapagliflozin in patients with type 2 diabetes and stages $3 b-4$ chronic kidney disease. Nephrol Dial Transplant. 2018;33(11):2005-11.

49. Yale JF, Bakris G, Cariou B, Nieto J, David-Neto E, Yue D, et al. Efficacy and safety of canagliflozin over 52 weeks in patients with type 2 diabetes mellitus and chronic kidney disease. Diabetes Obes Metab. 2014;16(10):1016-27.

50. Striepe K, Jumar A, Ott C, Karg MV, Schneider MP, Kannenkeril D, et al. Effects of the selective sodium-glucose cotransporter 2 inhibitor empagliflozin on vascular function and central hemodynamics in patients with type 2 diabetes mellitus. Circulation 2017;136(12):1167-9.

51. Lytvyn Y, Bjornstad P, Udell JA, Lovshin JA, Cherney DZI. Sodium glucose cotransporter-2 inhibition in heart failure: potential mechanisms, clinical applications, and summary of clinical trials. Circulation. 2017;136(17):1643-58

52. Baartscheer A, Schumacher CA, Wüst RCI, Fiolet JWT, Stienen GJM, Coronel R, et al. Empagliflozin decreases myocardial cytoplasmic $\mathrm{Na}(+)$ through inhibition of the cardiac $\mathrm{Na}(+) / \mathrm{H}(+)$ exchanger in rats and rabbits. Diabetologia. 2017;60(3):568-73.

53. Uthman L, Baartscheer A, Bleijlevens B, Schumacher CA, Fiolet JWT, Koeman A, et al. Class effects of SGLT2 inhibitors in mouse cardiomyocytes and hearts: inhibition of $\mathrm{Na}(+) / \mathrm{H}(+)$ exchanger, lowering of cytosolic $\mathrm{Na}(+)$ and vasodilation. Diabetologia. 2018;61(3):722-6.

54. Cingolani HE, Ennis IL. Sodium-hydrogen exchanger, cardiac overload, and myocardial hypertrophy. Circulation. 2007;115(9):1090-100.

55. Ferrannini E, Muscelli E, Frascerra S, Baldi S, Mari A, Heise T, et al. Metabolic response to sodium glucose cotransporter 2 inhibition in type 2 diabetic patients. J Clin Invest. 2014;124(2):499-508.

56. Verma S, McMurray JJV. SGLT2 inhibitors and mechanisms of cardiovascular benefit: a state-of-the-art review. Diabetologia. 2018;61(10):2108-17.

57. Vallon V, Platt KA, Cunard R, Schroth J, Whaley J, Thomson SC, et al. SGLT2 mediates glucose reabsorption in the early proximal tubule. J Am Soc Nephrol. 2011;22:104-12.

58. Chao EC, Henry RR. SGLT2 inhibition - a novel strategy for diabetes treatment. Nat Rev Drug Discov. 2010;9(7):551-9.

59. Fioretto P, Zambon A, Rossato M, Busetto L, Vettor R. SGLT2 inhibitors and the diabetic kidney. Diabetes Care. 2016;39(Suppl 2):165-71.

60. Elmore LK, Baggett S, Kyle JA, Skelley JW. A Review of the efficacy and safety of canagliflozin in elderly patients with type 2 diabetes. Consult Pharm. 2014;29(5):335-46.

61. Mosleh W, Sharma A, Sidhu MS, Page B, Sharma UC, Farkouh ME. The Role of SGLT-2 inhibitors as part of optimal medical therapy in improving cardiovascular outcomes in patients with diabetes and coronary artery disease. Cardiovasc Drugs Ther. 2017;31(3):311-8.

62. Savarese G, D'Amore C, Federici M, De Martino F, Dellegrottaglie S, Marciano C, et al. Effects of dipeptidyl peptidase 4 inhibitors and sodium-glucose linked cotransporter-2 inhibitors on cardiovascular events in patients with type 2 diabetes mellitus: a meta-analysis. Int J Cardiol. 2016 Oct 1;220:595-601.

63. Wu JHY, Foote C, Blomster J, Toyama T, Perkovic V, Sundström J, et al. Effects of sodium-glucose cotransporter-2 inhibitors on cardiovascular events, death, and major safety outcomes in adults with type 2 diabetes: a systematic review and meta-analysis. Lancet Diabetes Endocrinol. 2016;4(5):411-9

64. Monami M, Dicembrini I, Mannucci E. Effects of SGLT-2 inhibitors on mortality and cardiovascular events: a comprehensive meta-analysis of randomized controlled trials. Acta Diabetol. 2016;54(1):19-36.

65. Zelniker T, Wiviott SD, Raz I, Im K, Goodrich EL, Bonaca MP, et al. SGLT2 inhibitors for primary and secondary prevention of cardiovascular and renal outcomes in type 2 diabetes: a systematic review and meta-analysis of cardiovascular outcome trials. Lancet. 2019;393(10166):31-9.

66. Zou C, Liu XK, Sang YQ, Wang B, Liang J. Effects of SGLT2 inhibitors on cardiovascular outcomes and mortality in type 2 diabetes: A metaanalysis. Medicine. 2019;98(49):e18245.

67. Birkeland K, Jørgensen ME, Carstensen B Persson F, Gulseth HL, Thuresson $\mathrm{M}$, et al. Cardiovascular mortality and morbidity in patients with type 2 diabetes following initiation of sodium-glucose co-transporter-2 inhibitors versus other glucose-lowering drugs (CVDREAL Nordic): a multinational observational analysis. Lancet Diabetes Endocrinol. 2017;5(9):709-17. 